\title{
Suppression and recovery of a human response as a function of the temporal order of reward and punishment'
}

ROBERT D. HARE

UNIVERSITY OF BRITISH COLUMBIA

Punishment (shock) administered during or after reward (interesting pictures) produced greater suppression of $a$ human response than did punishment administered prior to reward. These results indicate that the degree of responsesuppression depends upon the temporal arrangement of reward and punishment.

Recent research with human Ss suggests that delayed punishment may be less effective than immediate punishment in producing suppression of a response that has been established in the laboratory (Banks \& VogelSprott, 1965) or during the course of language acquisition (Hare, 1965). However, recent discussions of punishment (Church, 1963; Logan \& Wagner, 1965; Solomon, 1964) indicate that the effect of delayed punishment may depend upon whether or not reward is concurrently administered, and if so, upon the temporal order in which the reward and punishment are presented. In the study by Banks \& Vogel-Sprott (1965), punishment was administered for an instrumental response that continued to receive immediate reinforcement, while the other study (Hare, 1965) involved punishment of a well established verbal response which received no tangible reinforcement. In the present study, the temporal arrangement of reward and punishment was manipulated by punishing a response before, during, or after the presentation of reward.

\section{Method}

Fifty male undergraduate voluteers were randomly assigned to five groups of $10 \mathrm{Ss}$ each. The $\mathrm{S}$ was seated in front of an upright panel in the center of which was a ground-glass screen. He was told that each time the small light above the screen came on he was to press one of the two switches in front of him, and, as a result a picture would appear on the screen. Depression of one switch (response A) always produced a 2 sec. glimpse of an interesting picture (nudes, action scenes, etc.) which changed from trial to trial. Depression of the other switch (response B) always produced the same uninteresting picture (an ad for "headache" pills). Prior to the first trial, $S$ was informed of the relationship between the switches and the type of picture produced, and was further told that after some of his responses he would receive an electric shock. The interval between response and presentation of the pictures was $2 \mathrm{sec}$. while the intertrial interval was $25 \mathrm{sec}$. Timing was electronically controlled. After 10 trials without shock, during which $\mathrm{S}$ was encouraged to try both switches, each A-response resulted in a $500 \mathrm{msec}$. shock through finger electrodes attached to the nondominant hand. The interval between this A-response and the delivery of shock was $0,2,4,7$, and 10 sec., depending upon which group $S$ was in. Since the pictures always appeared 2 sec, after a response, shock for the Ss in 2 and 4 sec. groups was coincident with the picture's onset and offset respectively. Each A-response, by activating a stepping-relay coupled to a rheostat, increased the intensity of shock by a small amount. The intensity ranged, in 35 steps, from a level that was barely perceptible to one that was very painful for most Ss. The increase was approximately linear for the first 25 trials, but the remaining increments became progressively smaller. Punishment training continued until $S$ reached the suppression criterion of 10 consecutive B-responses (selection of the dull, non-shocked picture), or until he had made a total of 35 A-responses. A recovery period of 40 trials without shock followed punishment training.

\section{Results}

An average of $65-75 \%$ of the responses made by Ss in each group during the pre-shock period were A-responses. During the latter part of this period and the early stages of punishment training (when shock was mild), most Ss consistently pressed switch A. As the shock intensity increased however, B-responses became more frequent. The suppression criterion of 10 consecutive B-responses was reached by eight Ss in each of the 0,2 , and 4 sec. groups, by nine Ss in the $7 \mathrm{sec}$. group, and by all $10 \mathrm{Ss}$ in the $10 \mathrm{sec}$. group. The mean

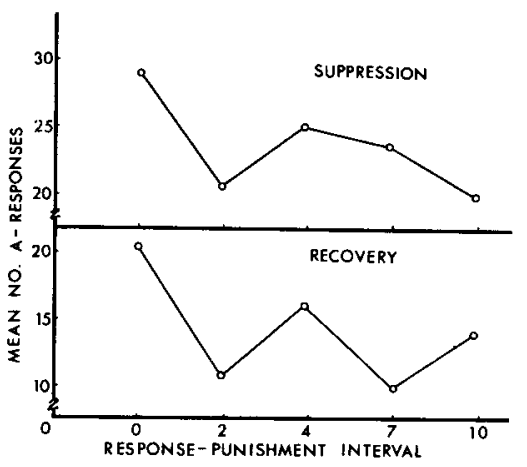

Fig. 1. The mean number of A-responses to suppression criterion and in $\mathbf{4 0}$ recovery trials as a function of the response-punishment interval. 
number of A-responses required by each group to reach this criterion is shown in Fig. 1. For purposes of statistical analysis, the seven Ss who failed to reach criterion by the 35 th A-response were assigned the value of 35 . An analysis of variance indicated that the groups differed significantly in the number of $\mathrm{A}-$ responses to criterion $(F=2.75, d f=4 / 45, p<.05)$. Individual comparisons between means, using the Scheffe test, revealed that only the 0 and 10 sec. groups differed significantly $(p<.05)$, although the difference between the 0 and $2 \mathrm{sec}$. groups and between the $2 \mathrm{sec}$. group and the average of the 0 and 4 sec. groups approached significance.

Recovery from the suppressing effects of shock was assessed by counting the number of A-responses made by each group during the 40-trial recovery period. The results are plotted in the bottom part of Fig. 1. The difference between means was significant at the .05 level $(F=2.71$, $d f=4 / 38)$. Individual comparisons indicated that the 0 sec. group differed significantly $(p<.05)$ from the 2 and $7 \mathrm{sec}$. groups. Some additional recovery data are of interest. In most cases, recovery was an all-or-none affair. Of the 43 Ss that reached criterion, $12(1,3,3,4$ and 1 in the $0,2,4,7$ and $10 \mathrm{sec}$. groups respectively) failed to make any A-responses during the recovery period. Only four Ss recovered gradually. The remaining 27 recovered very rapidly and completely as soon as they had made one or two A-responses. Discussion

On the basis of animal theory and research (see Church, 1963; Logan \& Wagner, 1965; Martin, 1963; Solomon, 1963), it might be expected that the presentation of punishment just before reward would allow the punishment to acquire secondary rewarding properties and to become an $\mathrm{S}^{\mathrm{D}}$ for the advent of reward. The result would be a reduction in the effectiveness of the shock as a punishment. The fact that the shock gradually increased in intensity from an initially low level adds to the plausibility of such an interpretation (see Martin, 1963). Similarly, the occurrence of reward prior to punishment would allow the reward to acquire secondary punishing properties and to become an $\mathrm{S}^{D}$ for the presentation of punishment. The result would be a reduction in the effectiveness of the reward.

The relatively great amount of suppression shown by the $2 \mathrm{sec}$. group may be due to several factors. The fact that in this group the onset of reward and punishment was simultaneous would make it improbable that the punishment would become an $\mathrm{S}^{\mathrm{D}}$ or acquire secondary rewarding properties. Further, it may be that under these conditions, a $S^{\prime} \mathbf{s}$ reaction to shock has a disruptive effect upon the processes involved in the perception of the picture, with the result that the reward value of the picture is reduced. This suggests that had reward been presented contiguously with punishment in one of the other four groups, a similar degree of response suppression would have been observed. The possibility must also be considered that at least part of the relatively great suppressing effects of immediate punishment reported by Banks \& Vogel-Sprott (1965) was due to the apparent suppressing properties of a punishment that is coincident with reward rather than to the existence of a delay-of-punishment gradient.

An alternative interpretation of the present findings is possible. It may be that delayed punishment retards the rate at which a response-punishment contingency is learned by humans (cf. Hare, 1965), but that once the contingency has been learned, the delayed punishment has greater aversive properties (or negative incentive; cf. Logan \& Wagner, 1965). For example, Hare (1966) found that when given a choice, human Ss may show a strong preference for immediate rather than delayed punishment. In a study, such as the present one, where the contingency is a relatively simple one to learn, a delayed punishment might be expected to have strong aversive properties and thus to produce a considerable amount of suppression. The deviation from a simple gradient effect shown by the $2 \mathrm{sec}$. group could be explained, as it was above, by assuming that punishment presented contiguously with reward results in a reduction in the value of the latter.

\section{References}

Banks, R. K., \& Vogel-Sprott, $\boldsymbol{M}$. Effect of delayed punishment on an immediately rewarded response in humans. J. exp. Psychol., $1965,70,357-359$.

Church, R. M. The varied effects of punishment on behavior. Psychol. Rev., 1963, 70, 369-402.

Hare, R. D. Suppression of verbal behavior as a function of delay and schedule of severe punishment. J. verbal Learn. verbal Behav., 1965, 4, 216-221.

Hare, R. D. Psychopathy and choice of immediate versus delayed punishment. J. abnorm. Psychol., 1966, 71, 25-29.

Logan, F. A., \& Wagner, A. R. Reward and punishment. Boston: Allyn \& Bacon, 1965.

Martin, B. Reward and punishment associated with the same goal response: a factor in the learning of motives. Psychol. Bull, $1963,60,441-451$.

Solomon, R. L. Punishment. Amer. Psychologist, 1964, 19, 239253.

\section{Note}

1. Supported by grant APA-139 from the National Research Council of Canada. The assistance of Terrence Creighton and Robert Phillips is appreciated. 